\title{
Relationship between Reflective Practice Skills and Volume of Writing in a Reflective Journal
}

\author{
Miho Tanaka ${ }^{1,2,3}$, Reiko Okamoto ${ }^{2,3}$, Keiko Koide ${ }^{3,4}$ \\ ${ }^{1}$ Sakai City North Health Center, Sakai, Japan \\ ${ }^{2}$ Division of Health Sciences, Graduate School of Medicine, Osaka University, Osaka, Japan \\ ${ }^{3}$ Former Graduate School of Health Sciences, Okayama University, Okayama, Japan \\ ${ }^{4}$ Faculty of Education, Shitennoji University, Osaka, Japan \\ Email: u398009a@ecs.osaka-u.ac.jp
}

How to cite this paper: Tanaka, M., Okamoto, R. and Koide, K. (2018) Relationship between Reflective Practice Skills and Volume of Writing in a Reflective Journal. Health, 10, 283-288.

https://doi.org/10.4236/health.2018.103022

Received: December 30, 2017

Accepted: March 12, 2018

Published: March 15, 2018

Copyright $\odot 2018$ by authors and Scientific Research Publishing Inc. This work is licensed under the Creative Commons Attribution International License (CC BY 4.0).

http://creativecommons.org/licenses/by/4.0/

(c) (i) Open Access

\begin{abstract}
Background: According to the diversification of the health needs and the expansion of health disparities, public health nurses need to improve their practical capabilities, starting from basic education in graduate and undergraduate courses. And Reflective Practice with using reflective journal is one way of improving practical capabilities. The purpose of this study was to investigate the relationship between the volume of reflective journal and the quality of progress in the reflective cycle. Methods: The participants in this study were 20 junior students majoring in public health nursing (hereinafter "PHN students") at a university in the Chugoku area, Japan. We asked the participants to answer the questions on Reflective Practice Skills (RPS) composed of six criteria corresponding to the six questions of Gibbs on the reflective cycle before and after they started writing RJ. The volume of reflective writing was measured by the number of characters written by the PHN students in RJ of the reflective practice for three months. The study plan was approved by the Ethics Committee for Nursing Study, Okayama University. Results: Although the average total RPS score showed a change of about 3 points as a result of the 3-month RJ writing exercise, no correlation was observed between the RPS score and the RJ writing volume $(\mathrm{r}=0.175)$. However, we did observe a moderately positive correlation between the RPS score and the RJ writing volume with regard to Items 5 and $6(r=0.475$ and $r=0.444$, respectively). Conclusion: This study indicated that detailed RJ writing helps to complete the reflective cycle all the way to theorization and action planning, and that the volume of writing may serve as a criterion for qualitative evaluation.
\end{abstract}

\section{Keywords}

Reflective Journal, Public Health Nursing Student, Reflective Skill 


\section{Introduction}

In recent years, the changing social environment in Japan has made health issues more diverse and complex, and so public health nurses need sophisticated practical capabilities in order to help prevent and resolve such issues. Accordingly, public health nurses need to improve their practical capabilities, starting from basic education in graduate and undergraduate courses.

Reflective Practice is one way of improving practical capabilities [1], and is increasingly being introduced in professional and school education along with Reflective Journal (hereinafter "RJ") and Portfolio [2]. Existing studies and surveys of public health nurses in Japan have shown the absence of a correlation between Reflective Practice Skills and years of experience [3], pointing to the need to consider evaluation and improvement measures to promote Reflective Practice more effectively, so that the accumulation of experience may lead to qualitative improvement in those skills.

The word "reflection" refers to any "activity to create expertise for responding to an unexperienced situation" through the process of Description, Feelings, Evaluation, Analysis, Conclusion and Action Plan [4]. Thus, to create high-quality expertise, it is necessary to focus on the progress throughout the reflective cycle and the content of reflection. A Reflective Practice Skills scale (hereinafter "RPS") has been developed as an objective measure of the quality of such progress [3]. However, no relationship has been identified between RPS, which evaluates the quality of the reflective cycle, and the quality of reflection itself.

Nakata et al. noted that insufficiency in the Description skill, which is required for writing, will prevent acquisition of the ability to recognize one's own Feelings, effectively precluding further progress in the reflective cycle [5]. In other words, the quality of reflection depends on whether one has the skill to recall one's own experience in detail and write it down. Since any reflective cycle must go through Description, we assumed that a certain volume of writing is required for every reflection exercise to ensure a certain level of quality in the content of reflection.

Thus, this study investigated the relationship between the volume of reflective writing and the quality of progress in the reflective cycle. The outcomes of the study included basic data on how to effectively improve Reflective Practice Skills.

\section{Methods}

The participants in this study were 20 junior students majoring in public health nursing (hereinafter "PHN students") at a university in the Chugoku area, Japan.

In order to measure the quality of progress in the reflective cycle, we asked the participants to answer the questions on RPS before and after they started writing RJ. A measure recognized for its internal consistency, RPS is composed of six criteria corresponding to the six questions of Gibbs [6] on the reflective cycle focusing on the volume of writing. The total score ranges from 6 to 36, with each 
question carrying a maximum of six points: one point for "Does not apply at all" and six points for "Completely applies".

The volume of reflective writing was measured by the number of characters written by the PHN students in RJ. As part of the three-month exercise to learn about public health nursing, the PHN students were required throughout the period to work on learning reflection by writing and submitting RJ on a weekly basis in principle. For RJ, we used the form developed in a pilot study drawing from Kolb's experiential learning model and Gibbs' reflective cycle: it comprised four sections, namely 1) Overview, 2) Questions for Verification, 3) Questions for Analysis and Evaluation and 4) From Theorization to Action Planning [7].

For the analysis, we used Microsoft Excel 2010 for simple aggregation of the volume of writing in RJ and the RPS score. We also used IBM SPSS Statistics 2.0 to analyze any correlation between the change in the RPS score after the start of RJ writing and the average number of characters per entry in RJ (Spearman's correlation analysis).

\section{Ethical Considerations}

The study plan was approved by the Ethics Committee for Nursing Study, Okayama University (approval No. T15-06, 7 October 2015). At the beginning of the academic year, we explained to the participants in the survey, both orally and in writing, that the submitted documents on reflection would be used after the completion of academic assessment for a study designed for educational improvement and that the contents of the documents were unrelated to the academic assessment. We obtained their consent by signing a comprehensive agreement by all participants.

\section{Results}

The age of the PHN students was 20 - 23 years old. As for the sex, female were 18 and male were 2 . And Figure 1 is a scatter diagram of the total RPS score after RJ and the RJ writing volume of $20 \mathrm{PHN}$ students.

The average total RPS score improved from 15.73 before the start of RJ writing to 18.90 at the end of the three-month exercise (Table 1). The average number of characters per entry in the submitted RJ (hereinafter "RJ writing volume") was $828.14 \pm 254.37$, with a difference of over 1,000 characters between the longest and the shortest entries (Table 1).

Although the average total RPS score showed a change of about 3 points as a result of the 3-month RJ writing exercise, no correlation was observed between the RPS score and the RJ writing volume $(r=0.175$; see Table 2). By item, there was no significant difference among the six items in terms of the increase in the RPS score, ranging from 0.40 to 0.65 . No correlation was observed, either, between the RPS score and the RJ writing volume for Items 1 to 4 ( $\mathrm{r}$ ranging from -0.127 to 0.283 ; see Table 2 ). However, we did observe a moderately positive correlation between the RPS score and the RJ writing volume with regard to 
Table 1. The average total RPS score and the average number of characters per entry in the submitted RJ $(\mathrm{N}=20)$.

\begin{tabular}{lccccc}
\hline & & Mean & SD & min & MAX \\
\hline The average total RPS score & Before RJ & 15.75 & 4.12 & 7 & 26 \\
& After RJ & 18.90 & 8.38 & 6 & 34 \\
The RJ writing volume & & 828.14 & 254.37 & 436 & 1549 \\
\hline
\end{tabular}

Spearman's Rank Correlation.

Table 2. Correlation between the RPS score and the RJ writing volume each item of RPS $(\mathrm{N}=20)$.

\begin{tabular}{|c|c|c|c|c|c|}
\hline Items & Mean & $\mathrm{SD}$ & $\min$ & MAX & $\mathrm{r}$ \\
\hline 1) I always write down, and check what I did and why I did it. & 0.45 & 1.47 & -2 & 4 & 0.022 \\
\hline 2) I always write down, and recall what I thought and felt about what I did. & 0.65 & 1.59 & -2 & 4 & -0.127 \\
\hline 3) I always write down, and evaluate what was good and bad about what I did. & 0.65 & 1.65 & -2 & 4 & 0.141 \\
\hline 4) I always write down, and analyze what sense I could make of what I did. & 0.50 & 1.57 & -2 & 4 & 0.283 \\
\hline $\begin{array}{l}\text { 5) I always write down what things I could have done better to help improve my } \\
\text { performance. }\end{array}$ & 0.50 & 1.47 & -2 & 3 & 0.475 \\
\hline 6) I always write down what I would do if the same situation arose gain. & 0.40 & 1.28 & -2 & 2 & 0.444 \\
\hline RPS Score Total & 3.15 & 8.22 & -11 & 21 & 0.175 \\
\hline
\end{tabular}

Spearman's Rank Correlation.

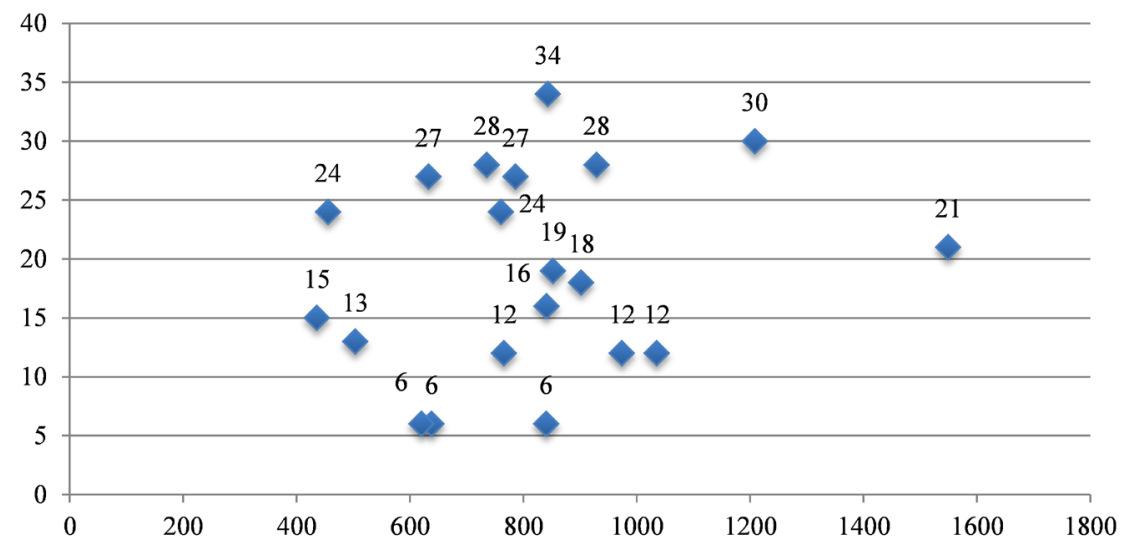

Figure 1. The scatter diagram of the total RPS score after RJ and the RJ writing volume of 20 participants $(\mathrm{N}=20)$.

Items 5 and $6(\mathrm{r}=0.475$ and $\mathrm{r}=0.444$, respectively; see Table 2). Figure 2 and Figure 3 are scatter diagrams showing the relationship of the RPS score and the RJ writing volume on the two items.

\section{Discussion}

As the results indicate, the average RPS score showed an improvement across the board after the RJ writing exercise.

Significant differences were observed for Items 5 and 6, which correspond to Conclusion and Action Plan in Gibbs' reflective cycle, respectively. This means 


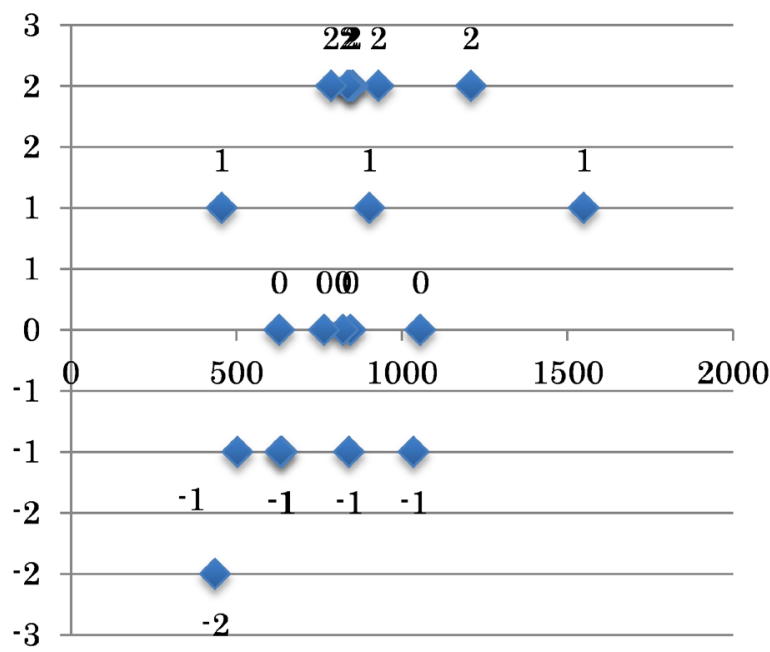

Figure 2. The correlation between the increase of RPS score and the RJ writing volume on No. $5(\mathrm{~N}=20)$.

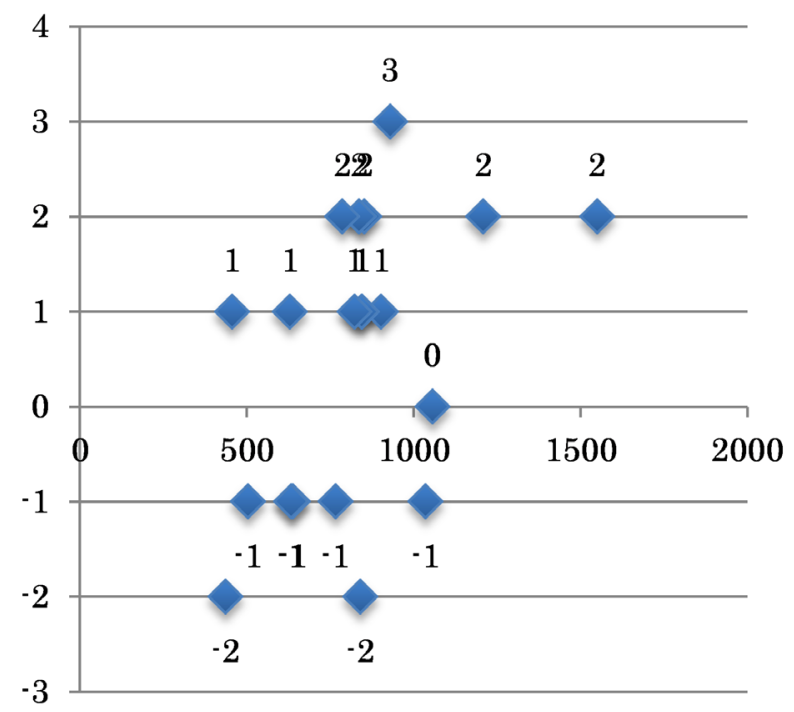

Figure 3. The correlation between the increase of RPS score and the RJ writing volume on No. $6(\mathrm{~N}=20)$.

that students who made more detailed entries in RJ were more likely to recognize that they could conduct the reflective cycle all the way to the stage of Conclusion or Action Plan. Since reflection refers to any "activity to create expertise for responding to an unexperienced situation", it is preferable that public health nurses can conduct the whole reflective cycle. Thus, it is natural that students who made more detailed entries in $\mathrm{RJ}$ were able to gain practical expertise.

Tamura et al. noted that reflection should "ideally be accompanied by the description of one's own experience that allows any unrelated third party to understand that experience as if he/she was there [6]". They also argued that writing creates a momentum in the reflective cycle, and hence promotes effective learning [6]. Furthermore, Nakata et al. indicated that RJ writing helps to articu- 
late the minute details of one's experience more easily. It may be assumed that students making detailed entries in RJ repeatedly tried to recall the details of their experience and describe their experience expressively with analogies and illustrations, which was apparently reflected in the volume of writing. Thus, the results indicate that the volume of RJ writing may be one of the criteria in evaluating the quality of reflection. It also suggests the importance of training on how to express things as they are.

In future, our findings will need to be validated by a qualitative and descriptive analysis of what is written in RJ.

\section{Conclusion}

This study indicated that detailed RJ writing helps to complete the reflective cycle all the way to theorization and action planning, and that the volume of writing may serve as a criterion for qualitative evaluation.

\section{References}

[1] Ministry of Education, Culture, Sports, Science and Technology. (2015) The Conference on Nursing Education in university. (In Japanese)

http://www.mext.go.jp/b_menu/shingi/chousa/koutou/40/

[2] Health and Welfare Division, Health and Welfare Department, the Conference on Constructing a Structure of Leadership Training for Trainers. (2010) The Program for Trainers of On-the-Job Training. The Report of Middle Public Health Nurse, Okayama, 26-30. (In Japanese)

[3] Okamoto, R., Koide, K., Maura, Y. and Miho, T. (2017) Realities of Reflective Practice Skill among Public Health Nurses in Japan and Related Learning and Lifestyle Factors. Open Journal of Nursing, 7, 513-523. https://doi.org/10.4236/ojn.2017.75040

[4] Gibbs, G. (1998) Learning by Doing: A Guide to Teaching and Learning Methods. Oxford Brooks University, Oxford.

[5] Tamura, Y. and Ikenishi, E. (2014) Activating Reflection in Nursing Education and Practice. Nankodo, Tokyo. (In Japanese)

[6] Nakata, Y., Tamura, Y., Shibuya, M., Hirano, Y., Yamamoto, N., Morishita, A., Ishikawa, Y. and Tsuda, N. (2003) The Significance of Early Introduction of Reflective Journal into Nursing Education: A Comparison of Reflective Skills Use between Two Cohorts of Students. The Bulletin of Kobe University School of Medicine Faculty of Health Science, 19, 27-32. (In Japanese)

[7] Okamoto, R. (2013) Development of Public Health Nursing Skills to Show the Necessity. Okayama University Press, Okayama, 34-140. (In Japanese) 